\title{
O desenho como prática de investigação científica: Da percepção ao desenho registro.
}

\author{
Drawing as a practice of scientific \\ investigation: From perception to drawing \\ registration.
}

\begin{abstract}
Poliana Santiago Sobral
Mestra em Desenho Cultura e Interatividade

UEFS - Universidade Estadual de Feira de Santana.

Feira de Santana - Brasil

polianassobral@hotmail.com

\section{Priscila Paixão Lopes}

Doutora em Biologia

Docente da UEFS -

Universidade Estadual de

Feira de Santana,

Departamento de Ciências

Biológicas. Feira de Santana-

Brasil

pplopes.uefs@gmail.com
\end{abstract}

\section{Gláucia Maria Costa}

Trinchão

Docente da UEFS -

Universidade Estadual de

Feira de Santana,

Departamento de Letras e

Artes

Fera de Santana-Brasil

gaulisy@gmail.com

\begin{abstract}
RESUMO
Este estudo é fruto de uma investigação no campo interdisciplinar entre as Ciências Naturais, Botânica, e o Desenho conhecimento, representação e técnica. Analisa o caminho perseguido pelo ilustrador botânico entre a percepção e a produção de uma ilustração científica, abordando aspectos filosóficos e gráficos. Através da adoção de um olhar fenomenológico acerca da percepção e da contribuição de alguns autores quanto às ideias de Desenho e de Ilustração Científica, pôde-se entender este tipo de ilustração como um instrumento possibilitador de um discurso científico sobre a natureza, a medida que nasce da percepção do naturalista ou botânico traduzida em elementos gráficos, e não como uma mera representação da realidade, mas como um produto e instrumento de pesquisa.
\end{abstract}

\section{Palavras-chave Ilustração Científica, Percepção, Desenho, Registro.}

\section{ABSTRACT:}

This study is a research in the interdisciplinary field between the Biological Sciences and the Design, and aimed to analyse the path from a perception to the production of a scientific illustration, approaching philosophical and graphic aspects. Through the adoption of a phenomenological view on the perception and the contribution of some authors to the ideas of Drawing and Scientific Illustration, this type of illustration could be understood as an enabling instrument of a scientific discourse about nature, as it is born of perception translated into graphic elements, and not as a mere representation of reality.

Keywords: Scientific Illustration, Perception, Design, Register. 


\section{INTRODUÇÃO}

0 presente texto se ocupa da relação interdisciplinar entre as Ciências Naturais e o Desenho, especialmente no que concerne à Botânica e aos Desenhos conhecimento, representação ou técnica, que permeiam a construção e a visualização dos resultados das pesquisas realizadas nessa área das ciências.

A interdisciplinaridade surge como uma forma de amenizar a fragmentação de saberes didaticamente separadas em áreas especificas para facilitar o trabalho do pesquisador ou educador na transmissão e socialização do conhecimento, seja por meio de seus estudos científicos ou em sala de aula, e assim aproximar campos científicos e profissionais que por natureza são ou interdisciplinares, como no caso aqui em questão. A “interdisciplinaridade se caracteriza pela intensidade das trocas entre os especialistas e pelo grau de integração real das disciplinas, no interior de um projeto específico de pesquisa" (JAPIASSU, 1976, p. 74).

Para pensar o contexto interdisciplinar é preciso, entretanto, salientar que ele continua a ser discutido no meio acadêmico e seu conceito ainda não está estabelecido claramente. Porém, o que fica evidente é a necessidade de se gerar diálogos entre os mais diversos campos do saber que, academicamente, foram gerados pela fragmentação do conhecimento com finalidades didáticas de socializar esse conhecimento. As ciências, como se apresenta, de forma "parcelares não dão conta de explicar a realidade, de explicar o mundo", daí "o desejo de reverter, em certa medida, as distorções que foram impostas à vida do cidadão em diferentes espaços geográficos, sociais e contextos históricos. " (PONTUSCHKA, 1999, p. 03).

Confluindo para este pensamento de Ponthuschka (1999) nota-se que apesar das duas áreas do conhecimento aqui abordadas, Ciências Botânicas e Desenho, serem tratadas nos espaços acadêmicos em separado, torna-se quase impossível separá-las no campo da pesquisa cientifica, na medida em há pontos em que elas se tangenciam e dialogam necessária e harmonicamente na hora de organizar, registrar e socializar os dados das pesquisas. Tendo em vista esta assertiva, busca-se mostrar como o Desenho produz e serve à produção do conhecimento científico, partindo da percepção investigativa da natureza até o seu registro gráfico, configurando, desta maneira, uma linguagem, que é também uma ciência e que, dentre outros atributos, serve à documentação de estudos próprios das Ciências Naturais, especialmente no campo da Botânica, assim como fonte de pesquisa e documento da história.

A percepção e o conhecimento são indissociáveis, afirmam Filósofos e cientistas modernos, como Merleau Ponty (1999) e Marturana \& Varela (1995), o que nos leva a pensar o papel do Desenho, no seu caráter de representação e registro, como importante ferramenta investigativa que gera conhecimento, visto que a sua prática possibilita uma aproximação com o 
objeto percebido por partir da observação minuciosa à posterior representação, através de elementos gráficos, daquilo que convém ser explicitado. Ao longo da história das ciências, em especial das ciências naturais, o Desenho se revelou elemento essencial para a produção e divulgação do conhecimento, desde um período em que não havia suporte fotográfico até os tempos atuais, nos quais a sua capacidade de síntese se mostrou insubstituível.

Portanto, entendendo a interdisciplinaridade como o desafio de aproximar campos diversos do conhecimento construindo no pesquisador e no educador uma reflexão crítica e inovadora do conhecimento, onde o sujeito pense a sua produção envolta em uma totalidade, em busca de quebrar ou diminuir a distância entre os fragmentos do conhecimento impostos pela academia, este estudo trata dessa relação entre Ciência e Desenho, analisando desde o caminho da percepção até o Desenho linguagem e como registro no âmbito das ciências naturais, em especial a Botânica.

\section{ILUSTRAÇÃO CIENTÍFICA - A INTERDISCIPLINARIDADE ENTRE DESENHO E A CIÊNCIA}

Entendendo o Desenho como uma linguagem, mas também como um campo do conhecimento, vislumbramos a comunicação entre ele e a Botânica como algo maior do que a apropriação de uma linguagem por um campo do saber, colocando ambos em um mesmo patamar estabelecemos a colaboração entre dois campos do saber, algo que é característico da interdisciplinaridade. Acreditando que a interdisciplinaridade se opõe a um saber fragmentado, propondo o diálogo entre campos do conhecimento até então dissociados, busca-se a simbiose entre duas áreas estabelecendo a construção de algo novo que reflita as características de ambas, aqui no caso a Ilustração Científica.

O Desenho pode ser entendido como uma ferramenta de investigação, percepção e registro por meio de formas que produzem imagens, e a ciência como uma forma de discurso que organiza o pensamento dentro de parâmetros lógicos se fiando na busca pela explicação de fenômenos de maneira metódica e sistematizada. A Ilustração Científica nasce, então, do cruzamento interdisciplinar entre o Desenho e a Ciência e exibe traços precisos e delimitados quase que didáticos, conduzindo o olhar através de características evidenciadas da realidade percebida pelo cientista investigador. Como linguagem, o Desenho viabiliza a comunicação das descobertas científicas por meio de criações de imagens visuais que não só complementam o texto, mas são por si só fontes de informação científica e documentos da história das ciências.

A ilustração científica, portanto, “é um tipo de representação figurativa cujas finalidades são registrar, traduzir e complementar, por meio da imagem, observações e experimentos científicos que vão desde a descrição de espécies microscópicas de animais e vegetais até a anatomia humana". Essa representação figurativa, perpassa também "pela arqueologia, paleontologia, 
mineralogia, geologia, cartografia, astronomia, arquitetura, física, engenharia e história natural de uma infinidade de seres vivos e sua relação com a paisagem ou nichos onde vivem (FORD, 1992, p.1).

Assim, quando o Desenho encontra o campo do saber científico, tornase ferramenta de produção de conhecimento, suas características denotam um olhar investigativo por trás de traços precisos e demonstrativos. Numa única prancha de ilustração o desenhista é capaz de apresentar inúmeros aspectos de uma espécie estudada, aspectos macro e microscópicos são dispostos numa organização didática com uma finalidade informativa. 0 grande trunfo deste trabalho está na possibilidade de composição ao gosto do ilustrador, como evidencia Araújo et al. (2010, p.01), "ao produzir uma ilustração científica o desenhista tem a liberdade de montar uma prancha com as características de interesse, ou seja, com estruturas e detalhes evidenciados e associados da forma que mais convém."

Cabe salientar que os programas de edição de imagem são grandes facilitadores da montagem de pranchas ilustrativas, nos dias atuais, pois através deles é possível fazer uma composição que convenha à sua utilização, bem como corrigir erros gráficos identificados pelo ilustrador caso a ilustração tenha sido feita nos moldes tradicionais. Outra possibilidade viabilizada por programas de edição é a utilização da fotografia na confecção de pranchas de ilustração botânica, através da separação dos elementos que caracterizam a espécie, técnica é pouco utilizada mas pode ser encontrada em alguns trabalhos como é o exemplo da ilustradora Niki Simpsom ${ }^{1}$.

${ }^{1} 0$ trabalho desta ilustradora pode ser encontrado no seguinte endereço eletrônico:

https://www.visualbotany.co.uk 
Imagem 1 - Ilustração Botânica a Nanquim de Amburana cearensis,

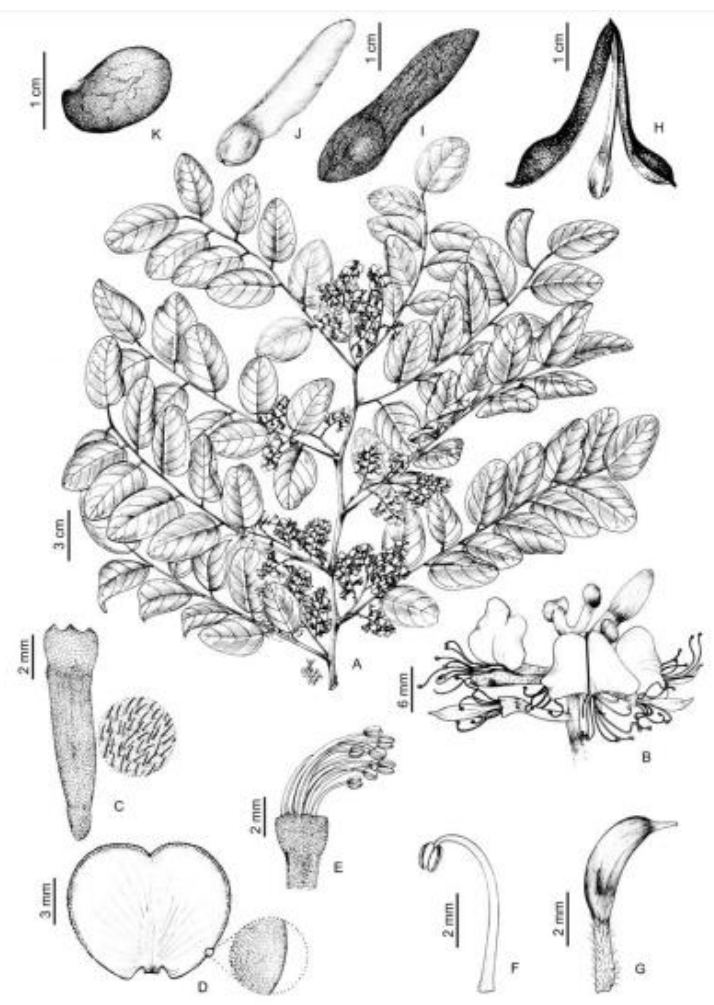

Fonte: Ilustração Carla Lima. (CARDOSO, 2008).

O objetivo das pranchas ilustrativas é mostrar para o leitor do trabalho científico as características diagnósticas de uma espécie. Este tipo de desenho está alinhado com as ilustrações realizadas no século XVIII, respondendo ao modelo classificatório de Lineu ${ }^{2}$. Este modelo permanece em vigência, apesar das ciências biológicas terem se modificado bastante do período setecentista para o atual, principalmente no que concerne à percepção de que os seres vivos evoluem, entretanto o paradigma evolutivo tornou ainda mais necessário o registro das espécies, sendo que o agrupamento dos seres vivos depende da percepção de semelhanças e dessemelhanças entre grupos de indivíduos e estas características, unidas às análises moleculares, podem apontar para um possível caminho evolutivo entre eles.

Não é apenas este modelo de ilustração que compõe o acervo das ilustrações botânicas. Outro legado nos foi deixado por ilustradores que apareceram ainda no século XVIII em contraposição ao Modelo classificatório de Lineu, ao se harmonizar com as ideias de Humboldt ${ }^{3}$. Os trabalhos feitos por eles buscavam mostrar a interação entre as espécies em lugar de coloca-las separadas do seu

\footnotetext{
${ }^{2}$ Carl von Linné, foi um botânico, zoólogo e médico sueco, criador da nomenclatura binomial e da classificação científica .

${ }^{3}$ Alexander von Humboldt, foi um geógrafo, naturalista e explorador nascido na Prússia, atual Alemanha.
} 
entorno, coadunando-se com uma versão mais ecológica da ciência botânica que já começava a se delinear naquele período. Na atualidade os dois tipos de ilustração convivem servindo a diferentes propósitos ilustrativos e investigativos. Uma ilustradora é extremamente importante no contexto das ilustrações que retratam interações ecológicas a ilustradora Margaret Mee ${ }^{4}$, cujas obras até hoje inspiram ilustradores botânicos ao redor do mundo.

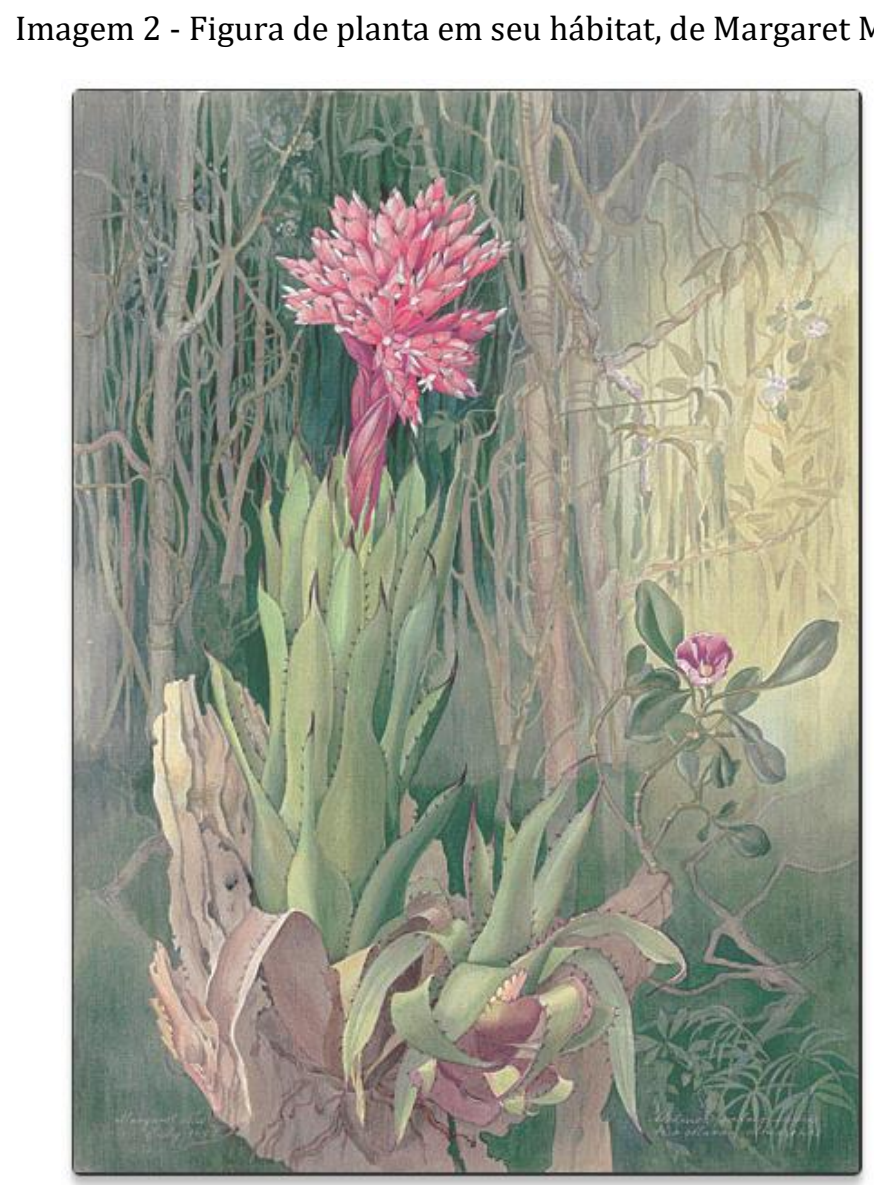

Fonte: https://netnature.wordpress.com/2014/06/16/margaret-mee-esua-contribuicao-artistica-para-a-ciencia-no-brasil

Portanto, a Ilustração Científica "constitui em si uma ferramenta extremamente útil, versátil e poderosa para a produção do conhecimento cientifico. E pode fazer parte também do processo de aprendizagem, de educação e de construção do conhecimento do Indivíduo (cognoscitivo), contribuindo para o progresso da Sociedade/Cultura (memória/repositório visual do entendimento à época). (CORREIA, 2011, p. 225.).

Assim, mais do que um contributo das artes na divulgação do trabalho científico, a ilustração científica pode funcionar como ferramenta didática, e é utilizado em sala de aula por professores de Ciências Naturais, pois, ao que

4 Margaret Ursula Mee, foi uma ilustradora Inglesa que morou no Brasil e se tornou uma referência para a ilustração botânica ao ilustrar biomas brasileiros, deixando para traz um grande acervo de ilustrações, principalmente de orquídeas e bromélias da região amazônica. 
parece, a observação e o registro de formas vivas significa uma importante maneira de assimilação cognitiva, visto que, como já mencionado, o ato de desenhar gera maior proximidade com o objeto observado.

Em contrapartida, ao mesmo tempo em que o Desenho contribui para as Ciências Naturais, elas doam a ele o seu olhar investigativo que se manifesta em uma forma de desenhar com peculiaridades que a distingue de outros tipos de expressão gráfica. A Ilustração Científica tem por regra principal ser um tipo de Desenho demonstrativo e sem ambiguidades. A mensagem que veicula deve estar atrelada aos interesses do estudo a que serve, sendo, sobretudo, didática. "O importante é lembrar que o tipo de imagem que chamamos ilustração científica deve ser útil à caracterização de um objeto, sem teoricamente conter ambigüidade". Ou seja, não cabe à Ilustração Científica permitir interpretações, "por parte do leitor, diferente daquela que o cientista deseja transmitir". (OLIVEIRA, 2004, p.1)

Apesar desta responsabilidade com o real, não devemos confundir este desenho com a realidade do objeto percebido, já que ele serve a um propósito, e, portanto, nesta empreitada, criação e percepção caminham juntas, não como na criação artística que dá a liberdade de inventar estruturas, mas através da criação de um ambiente e de uma configuração que melhor apresentem o detalhamento morfológico da estrutura vista pelo ilustrador, que fará de tudo para representar da maneira mais aproximada o que ele vê. Dentro do campo da botânica este tipo de Desenho tem um espaço fundamental e oferece, com grande riqueza de detalhes o que é de interesse da pesquisa.

\section{Desenho: o que é?}

Para poder explicar mais adiante a relação entre Desenho e percepção, vamos à origem da palavra Desenho para que se entenda o que é ou quais são as concepções possíveis sobre Desenho. Em busca da gênesis da palavra Desenho percebe-se que a sua origem é italiana e vem do verbo designare, que por sua vez, vem do latim de signum, que quer dizer marcar de maneira distinta, representar, designar, arranjar (GOMES,1996). Entretanto, este mesmo vocábulo abrange uma dupla conotação tanto material, quanto mental, e teve uma evolução diferente em vários idiomas, sendo que no português, a dupla conotação permanece atrelada a uma única palavra "Desenho", diferente do inglês, em que cada uma das ideias deu origem a uma palavra diferente: "draw" para uma conotação mais material e "design" para uma conotação mais mental. Por face material, entendem-se aquelas concepções que envolvem a representação gráfica, e por face mental entendem-se aquelas que dizem respeito aos aspectos que envolvem as imagens mentais, configuração e percepção. (ISODA, 2013).

Ao longo da história as ideias sobre Desenho sofrem inúmeras influencias e se moldam de acordo com as necessidades sociais e o uso que se faz dele. Uma das concepções de Desenho que nos permite uma aproximação 
com a sua essência por abranger as duas faces (Material e Mental) descritas por Isoda (2013), é a de Ramos (2015), que afirma:

\begin{abstract}
O desenho é, sobretudo a representação de algo, seja num suporte material, seja na própria mente, seja do visto, seja do imaginado; é manifestação; é síntese; é concepção; é signo e, como tal, é uma das formas do ato sêmico, definido como aquele dotado de intencionalidade. (RAMOS, 2015, on-line).
\end{abstract}

Desta afirmativa destaca-se que além do seu caráter representativo, o Desenho corporifica ideias e visões de mundo, já que é carregado da intencionalidade de quem o produz. Ele dá vida a uma nova forma a ser percebida, que, por sua vez, conterá um discurso intencional por parte do seu autor e será lido de acordo com o repertório do receptor. No tocante à ilustração científica deve-se sempre ter atenção para este aspecto, visto que muitas vezes pretende-se veicular a ideia de imparcialidade, que sabemos ser utópica. Por mais que se almeje fidelidade ao objeto desenhado, a maneira como se desenha e aquilo que se escolhe representar já refletem a intencionalidade de quem desenha. De acordo com Trinchão e Oliveira, 1998.

\begin{abstract}
O desenho é uma expressão gráfica que pode ser materializada de diversas formas e dimensões (no espaço bi e tridimensional real) para representar uma ideia ou para transmitir informações que resultaram na materialização espacial concreta desta ideia. Mesmo que através dos avanços da informática, da simulação matemática, da computação gráfica e da realidade virtual. (TRINCHÃO e OLIVEIRA, 1998, p. 163).
\end{abstract}

Não importa o suporte, ou os meios para construí-lo o Desenho sempre dará corpo a uma intenção preliminar. Mas, para que ele possa ser produzido, lido e interpretado, não se pode ignorar os seus elementos formativos e o que a nossa percepção gera em resposta a eles. Para Wong (2001):

\footnotetext{
Os elementos na verdade estão muito relacionados entre si e não podem ser facilmente separados em nossa experiência visual geral. Tomados individualmente, podem parecer um tanto abstratos, mas juntos determinam a aparência e conteúdo finais de um desenho (Wong, 2001, p. 42).
}

Feitas estas considerações, que refletem o entendimento da percepção como algo mais complexo do que a coleção de estímulos advindos do mundo externo, o autor, a nível de didática, distingue quatro grupos de classificações dos elementos que podem gerar uma aproximação à linguagem do Desenho, são eles: Os elementos conceituais - ponto, linha, plano e volume; os elementos visuais - formato, tamanho, cor e textura; os elementos relacionais - direção, posição, espaço e gravidade e finalmente os elementos práticos - representação, significado e função. É através destes elementos que a comunicação visual se faz possível, visto que possibilitam a tradução de elementos conceituais em representação visível no mundo físico. A este respeito Wong (2001) pondera: 
Quando desenhamos um objeto no papel, empregamos uma linha que é visível para representar uma linha que é conceitual. A linha visível não só tem comprimento como tem largura. Sua cor e textura são determinadas pelos materiais que usamos e pela maneira como o fazemos (Wong,2001, p. 43).

Depois da representação visual daquilo que é conceitual o observador fará uma leitura daquilo que é visto extraindo dali um significado, completando o ciclo que caracterizará o Desenho como uma linguagem. Quanto à especificidade do Desenho enquanto linguagem, Gomes (1996) salienta:

O Desenho é uma das formas de expressão humana que melhor permite a representação das coisas concretas e abstratas que compõem o mundo natural ou artificial em que vivemos. 0 exercício sistemático desse tipo de expressão nos dá condições de discernir e expandir o conhecimento e a consciência crítica sobre a qualidade, a funcionalidade e a estética dos ambientes que nos abrigam, dos artefatos que nos servem e das mensagens com que nos comunicamos (GOMES, 1996, p.13).

Desenho, portanto, é o registro daquilo que se percebe interna e externamente, é também a própria configuração do que se percebe através dos sentidos e da imaginação, é gerar sentido àquilo que se vê através da delimitação entre forma e fundo, da separação de elementos dentro de limites configurativos, que se dão a ver através da expressão em formas gráficas. Se transfigura em linguagem a partir do momento em que pode ser decodificado por um leitor que extrai dele um significado através de associações internas com o repertório de formas conhecido.

Destarte, o Desenho não só nos permite a representação daquilo que percebemos, mas também é uma ferramenta de gerar conhecimento acerca do que é desenhado. Mais do que construir um discurso sobre o mundo, o ato de desenhar gera uma familiaridade com ele. 0 olho do desenhista percorre o seu objeto e minunciosamente o desvenda, não se trata do olhar vulgar que lançamos a todo momento às coisas, mas um olhar investigativo que nos carrega aos mínimos detalhes do que percebemos gerando em nós conhecimento.

\subsection{Percepção e desenho: uma relação interativa na prática investigativa cientifica.}

Sabe-se que há uma relação muito intima entre o Desenho e a percepção, sendo que muitas vezes fica difícil segregar estas ideias. A relação entre a percepção e o Desenho, especialmente na prática da Ilustração Científica, revela como alguns filósofos fenomenologistas pensam a apreensão do conhecimento, e como o Desenho, enquanto modo de ver e registrar, atua 
neste processo de construção e documentação do conhecimento produzido pelas Ciências Naturais.

Conhecer a natureza é uma das principais necessidades do homem desde os seus primórdios, tendo em vista que ele está imbrincado nela de maneira indissociável, é dela que ele retira o seu sustento, sua alimentação, é nela que realiza todas as suas atividades, é dela que tira a matéria prima para produzir todos os objetos que utiliza no seu cotidiano, e é também ela que se apresenta ao seu olhar em formas, cores, sabores, texturas e sons. Portanto, conhecer a natureza é uma questão de sobrevivência, de tecnologia e também de estética. Mas de que maneira é possível conhece-la?

A experiência dos sentidos, a percepção, que se faz num processo de interação entre o indivíduo e o meio em que vive produz o conhecimento. De acordo com Maturana e Varella (1984) só se pode perceber o conhecimento humano a partir dele mesmo, pois para estes autores não se pode conhecer objetivamente o mundo independente daquele que realiza tal atividade, pois a vida é um processo de conhecimento. "Se a vida é um processo de conhecimento, os seres vivos constroem esse conhecimento não a partir de uma atitude passiva e sim pela interação. Aprendem vivendo e vivem aprendendo". (MATURANA e VARELLA, 1984, p.12). Essa perspectiva tautológica do conhecimento se assemelha àquela fenomenologia da percepção fomentada por Merleau Ponty, que aponta a percepção como um complexo de interações entre aquilo que se dá a ver e o próprio indivíduo que percebe, e não uma impressão causada pelo objeto no indivíduo, como pensavam os empiristas. Em consonância, com estas ideias, Chauí (2000) fala da percepção de acordo com os fenomenologistas e destaca, além de outras assertivas que quebram com o pensamento filosófico tradicional, que a percepção, é o conhecimento de um sujeito corporal, isto é, uma vivência corporal, de modo que a situação de nosso corpo e as condições de nosso corpo são tão importantes quanto a situação e as condições dos objetos percebidos.

Ambos os pensamentos nos mostram que estamos imiscuídos no processo do conhecimento, o que leva a crer que aquilo que apreendemos do nosso entorno depende também da maneira como posicionamos o nosso olhar diante do mundo. Ao desenhar, um desenhista naturalista, apreende o seu objeto de estudo de maneira criteriosa e minuciosa, expandindo a sua percepção para além de um olhar corriqueiro. 0 desenhar se caracteriza por um "processo curioso, tão interligado ao processo de ver que seria difícil separar os dois. A capacidade de desenhar depende da capacidade de ver como um artista vê - e esta maneira de ver pode enriquecer enormemente a vida de uma pessoa. (EDWARDS, 1979, p.12).

Tendo em vista que a percepção é quem nos fornece todo repertório de conhecimento e ação sobre o mundo, é de grande relevância destacar a atitude de desenhar como fundamental para o conhecimento da natureza, o que leva muitos professores da área de ciências naturais a exercitarem este tipo de atividade com seus alunos. A prática do Desenho fornece o tipo de olhar 
investigativo do qual carecem as ciências naturais, por se tratarem de um campo de pesquisa em que o detalhamento do objeto de estudo é imprescindível para que se tracem relações, diferenças e conexões entre estruturas das mais diversas espécies existentes no planeta.

Mas para além do perceber, o homem quer comunicar. Deseja registrar e documentar aquilo que percebe, para si e para os outros, já que é eminentemente um ser social, e para isso necessita das linguagens que se configuram nas mais diversas formas de expressão e recepção. E aqui o Desenho cumpre a sua função de registro e de memória, sendo ele uma das mais antigas linguagens utilizadas pelo homem, e ainda fortemente presente no seu meio.

\section{Ilustração científica - percepção da natureza traduzida através de} elementos gráficos.

A percepção e o conhecimento estão intimamente ligados dentro das concepções fenomenologistas, e como visto no tópico anterior através do Desenho é possível dilatar a percepção para que esta forneça os elementos necessários à representação da natureza. Porém, deve-se levar em consideração que apesar da busca pela aproximação com a realidade da ilustração científica devemos nos lembrar que ela surge pela combinação dos elementos do Desenho. Neste tópico discutiremos como a percepção da natureza se incorpora em elementos gráficos, gerando aquilo que chamamos de ilustração científica.

Em primeiro lugar cabe delimitar que a ilustração é apenas um tipo de aplicação do campo de conhecimento do Desenho. Ela diz respeito a um desenhar vinculado a outro tipo de linguagem. Entretanto, ela não é apenas um acessório ou complemento, como muitas vezes é tratada, pois é dotada de um discurso próprio, como bem colocado por Arbach, 2011:

\footnotetext{
Percebemos, assim, o quanto é apropriado o termo ilustração, ou primitivamente iluminura, para esclarecer e iluminar um texto, trazendo para a luz aquilo que se encontrava velado. Os elementos a serem utilizados pelo ilustrador não estão diretamente ligados às palavras, mas aos espaços existentes entre elas. É nesse espaço vazio indefinido, no lusco-fusco crepuscular entre uma palavra e outra que a ilustração se revela (ARBACH, 2011, p. 46).
}

Em se tratando de ilustração botânica, aquilo que o autor denomina de espaço vazio, se manifesta na incapacidade de se traduzir através de palavras, detalhes morfológicos dos grupos vegetais, abrindo espaço na pesquisa para a inclusão de desenhos descritivos aos quais cabem a tarefa de apresentar, ou "iluminar" o objeto através de um tipo diferente de estímulo.

Através da ilustração científica se torna possível construir conhecimento acerca na natureza, explorando suas minucias por meio de um olhar investigativo comum ao Desenho e à prática científica e se expondo 
através de elementos gráficos um recorte da profusão de estímulos que a percepção é capaz de fornecer.

Além da delimitação pela linha gráfica, a Ilustração Científica engloba outros elementos gráficos para gerar efeitos visuais de textura, luz e sombra, tridimensionalidade e forma. Tais elementos por si só, já são criações, ou melhor, traduções gráficas daquilo que é conceitual. De acordo com Rawson (1969):

\begin{abstract}
In a sense one can say that drawing is the most fundamentally spiritual - i.e., completely subjective - of all visual artistic activities. Nature presents our eyes with coloured surfaces to which painted areas of pigment may correspond, and with inflected surfaces to which sculptural surfaces may correspond. But nowhere does it present our eyes with the lines, and the relationships between the lines, which are the raw materials of drawing. For a drawing's basic ingredients are strokes or marks which have a symbolic relationship with experience, not a direct overall similarity with anything real (RAWSON,1969).
\end{abstract}

Corroborando com este pensamento, Arasse (2006) diz que o Desenho Cientifico "procura a representação da "forma exata" dos objetos, embora ela não seja discernível na natureza" e "É uma construção que inventa a objetividade fixa do objeto". Mas é justamente neste ponto que se encontra a grande contribuição do Desenho para este campo. Ele não traz aos olhos a "realidade", já que esta é mutável, ele traz aspectos da realidade que se quer preservar e fixar, afim de obter algum tipo de conhecimento acerca daquele estado da matéria, e apresentar ao que lê de uma maneira didática o seu discurso sobre o objeto de estudo. Acerca da percepção dos contornos na natureza, Da Vinci adverte no tratado sobre a pintura:

\footnotetext{
Se os contornos verdadeiros dos corpos opacos de confundem de perto, eles serão ainda menos visíveis de longe; e, como é pelos contornos que se revela a forma exata de todo corpo opaco, toda vez que a distância nos impedir de perceber o conjunto, a percepção de suas partes e contornos nos faltará ainda mais. (Da Vinci, apud. Arasse, 2006, p. 60).
}

Contornando o invisível que se faz presente, o Desenho científico faz o uso de elementos visuais que se inter-relacionam para dar forma a elementos que são conceituais, afim de gerar uma representação do seu objeto de estudo capaz de conter as informações desejadas pelo pesquisador. A componente criação entra novamente, não como uma faceta fantasiosa, mas como uma possibilidade de sintetizar em um único desenho o fruto de inúmeras observações. E, para além disso, há, aparentemente um desejo de conhecer a forma estruturante daquilo que se apresenta aos nossos olhos como movente. A linha permite expor uma configuração escondida no objeto vivo. Percepção, conhecimento e registro se inter-relacionam e quase se confundem no universo da ilustração científica visto que a percepção e o conhecimento se possibilitam e se recriam a cada momento enquanto que o registro dá corpo 
ao percebido/conhecido, não como uma replicação do real, mas como fruto de um olhar investigativo e discursivo acerca da realidade.

\section{CONSIDERAÇÕES FINAIS}

No fluir desta pequena viagem pela filosofia da percepção e pelas concepções e aplicações do Desenho, em especial na botânica, encontramos a ilustração científica como o resultado da troca interdisciplinar entre dois campos do saber: 0 Desenho e as Ciências Naturais. Como resultado desta alquimia, o discurso analítico e investigativo se reveste de linhas precisas e demonstrativas, que esperam conter valiosas informações daquilo que na natureza é móvel, misturado e, às vezes, inacessível aos olhos. Revela-se através do Desenho saberes construídos através das investigações científicas e investiga-se através do Desenho os objetos de importância das Ciências Naturais, ou seja, as formas vivas presentes na natureza. Portanto, o caminho entre a percepção e o desenho registro, configura mais do que a mera representação da realidade, consistindo em um processo cognitivo complexo que se desdobra num discurso dialógico e não estático, o que ao invés de diminuir o valor da ilustração enquanto documento, a põe num patamar ainda mais valorável dentro daquilo que as novas epistemologias da ciência vêm adotando como paradigma e que repercutiu nas ideias sobre a percepção. $\mathrm{Ou}$ seja, a ilustração age em favor da produção e documentação cientifica à medida que registra não apenas formas naturais preexistentes, mas as ideias e percepções em torno delas.

\section{REFERÊNCIAS BIBLIOGRÁFICAS}

ARBACH, Jorge. 0 discurso da ilustração. A3: Revista de Jornalismo Científico e Cultural da Universidade de Juiz de Fora, Juiz de Fora, v. 01, p.46-47, out. 2011. Semestral. Disponível em: <http://www.ufff.br/revistaa3/todas-asedicoes-2/revista-a301/>. Acesso em: 30 jun. 2017.

ARAÚJO et al. Aplicações da ilustração científica em Ciências Biológicas.

Campus Rio Claro - Instituto de Biociências - Ciências Biológicas. 2010

ARASSE, Daniel. Arte e Ciência: funções do desenho em Leonardo da

Vinci. In: Imagem e Conhecimento. FABRIS, Annatereza; KERN, Maria Lúcia

Bastos (org.). São Paulo: USPE. São Paulo, 2006, p.55-73. 
CARDOSO, Domingos Benicio Oliveira Silva. Taxonomia da tribo Sophoreae (Leguminosae, Papilionoideae) na Bahia, Brasil. Dissertação apresentada ao PPGBot - UEFS, 2008

CHAUÍ, Marilena. Convite à Filosofia. São Paulo: Ática, 2000.

WONG, Wulcius. Princípios de Forma e Desenho. São Paulo: WMF Martins Fontes, 2001.

CORREIA, Fernando. A ilustração científica: "santuário" onde a arte e a ciência comungam. Visualidades, Goiânia v.9 n.2 p. 221-239, jul-dez 2011. EDWARDS, Betty. Desenhando com o lado direito de cérebro / Betty Edwards ; [Trad] Roberto Raposo, Rio de Janeiro : Tecnoprint, 1979 FORD, BRIAN J. Images of science. A history of scientific illustration. Londres, The British Library, 1992.

GOMES, Luiz Vidal Negreiros. Desenhismo. 2a ed. Santa Maria: ed. da Universidade Federal de Santa Maria, 1996.

ISODA, Gil Tokio de Tani. Sobre desenho : estudo teórico-visual / São Paulo, 2013.

JAPIASSU, H. Interdisciplinaridade e patologia do saber. Rio de Janeiro: Imago, 1976.

MATURANA, Humberto \& VARELLA, Francisco. A árvore do conhecimento, as bases biológicas do entendimento humano, Editorial . Psy II, São Paulo,1995.

OLIVERA, Lysie dos Reis \& TRINCHÃO, Gláucia Maria Costa. A história contada a partir do desenho. In: SANTOS, Robérico Celso Gomes dos \& Edson Dias. Anais do Graphica 98. Feira de Santana: UEFS/ABPGDDT,1998. 
PONTUSCHKA, Nídia Nacib. Interdisciplinaridade: aproximações e

fazeres. Terra Livre: as transformações no mundo da educação, São Paulo, n. 14, 100-124, jan-jul 1999.

RAMOS, Menandro. Desenho: um ensaio de abordagem. In: FACED Faculdade de Educação da UFBA. Retirado de:

http://www.faced.ufba.br/ menandro/textos_mr.htm> Acesso em: 23 jun. 2015.

RAWSON, Philip. Drawing: The Appreciation of the Arts. London: Oxford University Press, 1969

\section{AGRADECIMENTOS}

Agradecemos a Universidade Estadual de Feira de Santana - UEFS, ao Programa de Pós-graduação em Desenho, Cultura e Interatividade-PPGDCI e à Capes, instituição financiadora da pesquisa aqui apresentada parcialmente. 